\title{
The Design and Implementation of an Educational Augmented Reality Application for Logical Circuit Design
}

Manuscript ID:

EDU-2020-09013393

Volume: 9

Issue: 1

Month: December

Year: 2020

P-ISSN: 2320-2653

E-ISSN: 2582-1334

Received: 26.08.2020

Accepted: 12.10.2020

Published: 01.12.2020

Citation:

Arıkan, Fatih, and Hasan Özgür. "The Design and Implementation of An Educational Augmented Reality Application for Logical Circuit Design." Shanlax International Journal of Education, vol. 9, no. 1, 2020, pp. 33-50.

DOI: https://doi.org/10.34293/ education.v9i1.3393

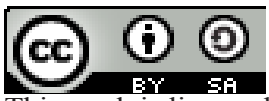

This work is licensed under a Creative Commons Attribution-ShareAlike 4.0 International License

\author{
Fatih Arıkan \\ Istanbul Rumeli University, Istanbul, Turkey
}

\author{
Hasan Özgür \\ Associate Professor, Department of CEIT, Faculty of Education \\ Trakya University, Edirne, Turkey \\ D https://orcid.org/0000-0002-8035-0320
}

\begin{abstract}
The purpose of the study is to determine the effect of augmented reality applications on the learning of engineering students in their professional courses. The objective of the study is to ensure that augmented reality technologies, which are among the most important technologies of today, are used in educational settings. The other important objective of the study is to ensure that the augmented reality technologies used in professional training in countries such as the USA, Canada and the Netherlands are also used in our country and to provide a world-class education opportunity. Also, contributing to the economy of our country with the successful studies to be carried out in this regard is among the objectives of the study because of the increasing interest in augmented reality software throughout the world and the formation of an important economy related to the development of these kinds of software.

In the study, an augmented reality application developed by the researcher was used in the learning process of a subject included in the faculty of engineering education curriculum. The study was performed using a convergent parallel mixed-methods design in which both qualitative and quantitative data were used simultaneously. The result of the study showed that there were no significant difference between the average attitude towards AR applications of the students participating in the study and the gender, class, and father education level; however, it is seen that there was a significant difference between maternal education status. It was also determined that the difference between the students' average attitude towards AR applications before and after the study was significant.

Similarly, it was observed that the difference between the AR attitude averages before and after the study and the AG attitude average 4 weeks after the study was also observed to be significant. It was also found that the students who participated in the study found the AR applications remarkable, entertaining, understandable and useful for the instructor. Moreover, they stated that using AR applications in lessons would contribute to fast and active learning and increase success.
\end{abstract}

Keywords: Augmented reality, Logical circuit design, Mobile application, Computer engineering

\section{Introduction}

With technological developments, the age we are in has started to be named the "Information and Communication Age". It is undeniable that besides technological developments, the introduction of these technologies in all areas of life has had a great impact on this naming. With this era of technology priority, the studies and transformations integrated into technological developments have begun to take place in the fields such as health, transportation, security, banking, communication, and shopping. Also, with the introduction of technology into educational settings, the importance of the use of technology in education has increased and technology has become an indispensable part of education (Seferoğlu, 2009). 
It is frequently stated that the use of technology in educational settings increases students' interest in the course and that the introduction of audio and visual facilities in educational settings using technological facilities facilitates the educational process (Korkmaz, 2013; Kreijns, et al, 2013; Shen, Liu \& Wang, 2013; Sumadio \& Rambli, 2010).

The need to attract the attention of a generation born into the technology that we call $\mathrm{Z}$ generation and whose communication with technology is very strong and increase their interest in educational settings also led to the necessity for educational settings to be developed in parallel with technological developments. Furthermore, the AR applications and the presence of other technological facilities in educational settings enable these individuals who follow and adapt to the technology in a short time to be trained as individuals who intertwine with the technology and use it much more efficiently (Güngördü, 2018).

Some of the negative results caused by the use of technology in education were also reached in the review of the literature. Matcha and Rambli (2013) state that technology in education reduces communication and interaction between students. In the same study, it is emphasized that there should be technologies that support the physical activities of the students. This led to the need for new tools that could be used in educational settings.

Considering these needs, Augmented Reality applications, which were founded by Ivan Sutherland in 1966, have become important, in particular with the developments in mobile devices (Sin \& BadiozeZaman, 2010; Tian, et al, 2014; Tomi \& Rambli, 2013; Zarzuela et al., 2013). Augmented reality is defined as supporting the real environment with virtual objects rather putting the person into a purely virtual environment (Bimber \& Raskar, 2005).

The AR applications are still considered to be an emerging technology. The necessity of having a certain level of technical knowledge for the development of AR applications and creating 3D models is one of the most important problems needed to be overcome for many trainers. However, this does not prevent trainers from working with developers who are conducting studies in the field.

This study was completed by making changes and updates in line with the opinions of academicians who are experts in the field during the AR application development process and were published for use in mobile devices.

This process of development and change have paved the way for the introduction of technologies such as Augmented Reality (AR) and Virtual Reality (VR), which are relatively expensive and rarely available and can only be used with special appliances and equipment in the past years, into the educational settings.

VR technology is a technology created in a computer environment that gives a sense of reality and with which the user can interact. The user enters the setting virtually created with all his/her senses, and his/her communication with the real world is restricted (İçten \& Bal, 2017). Augmented Reality (AR) is defined as a technology in which real settings can be supported by and interacted via virtual objects (Azuma, 1997). It is stated that AR applications facilitate learning and knowledge transfer, are effective in learning, and make abstract concepts easier to understand $(\mathrm{Wu}$, Lee, Chang, \& Liang, 2013). The fact that real objects and virtual objects created in AR applications can be seen in three dimensions and from all angles also facilitates learning. (Cheng \& Tsai, 2013; Hsiao \& Rashvand, 2011; Kerawalla, et al, 2006).

\section{Augmented Reality Applications in Education}

With the developments in AR applications, these applications have started to be used and widespread in the fields of military, medicine, engineering, entertainment, sports, advertising, tourism (Azuma, 1997; İbili \& Şahin, 2013; Kaufmann, 2003; Van Krevelen \& Poelman, 2010; Yen, et al, 2013). Of course, educational environments have been affected by all these developments and the number of AR applications developed for educational environments has also increased rapidly. The fact that AR applications have a flexible and developable structure that allows the preparation of educational materials that support learning by doing/experiencing makes these applications an important element for educational environments (Fleck, Simon \& Christian Bastien, 2014; Fleck \& Simon, 2013; Wojciechowski \& Cellary, 2013). 
AR applications are seen as advantageous in terms of providing innovation and interacting with content. In this regard, Bujak et al. (2013) stated that AR applications make it easier to understand and remember and are effective in increasing motivation. In addition to these beneficial features, training studies or experiments that cannot be performed in dangerous or educational environments can be performed with AR applications also reveals the necessity of these applications for educational environments (Eursch, 2007; Wojciechowski \& Cellary, 2013).

With developing web technologies, AR applications have become operable on internet browsers. LearnAR can be presented as an example of AR applications that can run on the Internet browser. On the LearnAR web page, there are applications prepared for mathematics, physics, chemistry, biology and foreign language lessons (LearnAR, 2015). ZooBurst, (About ZooBurst, 2015), Fetch! Lunch Rush (FETCH! Lunch Rush, 2015), Aurasma (Aurasma, 2015) can also be cited as examples of AR applications running on web browsers.

As in every field of education, AR technologies can be used in the education of disabled individuals. Bai, Blackwell, and Coulouris (2013) examined the effect of AR applications on the frequency and participation of autistic children to play dobelieve games, Zarzuela et al. (2013) developed AR supported zoo applications for disabled individuals. In the study conducted by Bai et al. (2013), it was observed that children using AR play games for a much longer time and participate more actively in practice. In Zarzuela et al. (2013) study, a virtual zoo was created for disabled students with the Unity 3D game engine. However, it was emphasized that this is not enough for developing AR applications and the necessity of add-ons such as Vuforia.

It has been observed that AR applications are used extensively in the field of Science Education as they allow the development of applications that include abstract concepts (Karal \& Abdüsselam, 2015). Similarly, it is stated that the use of AR contributes to learning in combating epidemic diseases in Science Education (Rosenbaum, Klopfer, $\&$ Perry, 2006). Half of these, Eursch (2007) aimed to make the dangerous working environment safer by developing an AR application used by personnel in nuclear studies.

\section{Aim of the Study}

In the related literature, although it is observed that AG applications have a wide range of applications in educational settings, the number of studies for undergraduate students is very limited. There is no study conducted about AR applications to contribute to the education process of the undergraduate students of the faculty of engineering. Therefore, it was decided to conduct a study to measure undergraduate students' perspectives on AG applications and its impact on their learning. It was decided to develop an application covering the subject of Logical Circuit Design. For this purpose, a mobile augmented reality application has been prepared for the subject of logic circuit design, which is among the courses of the faculty of engineering and made available to the students. The contribution of the mobile augmented reality application developed at the end of the education process to the students' learning of the relevant subject and their attitudes and other perspectives towards the AR applications are evaluated.

Within the framework of this general objective, the answers to the following questions are sought:

1. How are the attitudes of students towards augmented reality practices?

2. Is there any significant difference between the attitudes of students towards augmented reality applications and the variables of gender, mobile phone ownership, daily internet usage time, parents' education status?

3. How are the opinions of the students on the use of augmented reality applications in the courses?

\section{Development of Augmented Reality Application}

The development process of the AG application consists of two parts. The first part is creating 3D objects, QR cards, designing and preparing e-books to be used within the AG application. The second part is the development of an AG application into which the prepared objects will be integrated. The stages of planning, product development, working environment creation and prototyping are followed in both sections. 
The AR application developed to be used in this study has been developed with Unity 3D software. Unity 3D software, which is essentially described as a "game engine", is free software that makes it possible to develop applications that can run on different platforms and meet different needs. The applications developed with Unity 3D can be compiled to run on different platforms such as Windows, IOS, Android, Playstation and Xbox without making any changes to the application. In particular, because the applications developed for educational purposes are not a hardware standard in educational settings, the fact that the applications, which can have the same performance on different platforms, can also be developed draws attention as an important feature.

QR codes were created and placed in the application to determine the area where the images prepared for use in the study will be created. However, for the same QR codes to be detected by the camera, the necessity of preparing a visual document has arisen. In case of preparation of such a document, considering that its contents should have an interesting nature, it was concluded that it would be more useful to create an e-book by including the basic information about the subject of "Logical Circuit Design". For this purpose, an e-book has been prepared with Adobe InDesign software and shared with participants.

The modeling 3D objects and animations used in the application were made with 3DS Max software. The application works via the cameras of mobile devices without the requirement of additional hardware.

\section{Participants' Use of the Application}

Following the completion of the application development process, a meeting was held with the Computer Engineering Department of the Faculty of Engineering of Istanbul Rumeli University and information about the AR applications, the purpose of the study, and the use of the application was shared. After this pre-briefing, the application file with apk extension of the application developed was shared with the students to install the application on their smart devices. After making sure that the working set is ready, the e-book prepared for use with the application was shared with the students and the information about using it was provided to them.

\section{Research Model}

The research was conducted with a mixed methodical approach where quantitative and qualitative data were used together. The convergent parallel mixed method design was used in the research (Figure 1). In this approach, quantitative and qualitative data are collected together, and the findings are compared to determine whether the findings confirm each other (Creswell, 2013).

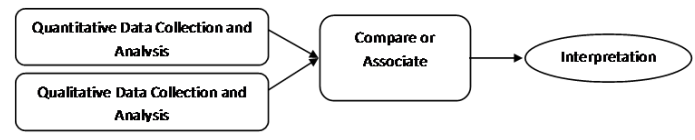

Figure 1: Convergent Parallel Mixed Method Design (Adapted from Creswell, 2013)

In the study, the pattern was applied in four stages and the collected data was evaluated (Table 1). In the first stage, the students were required to fill out a short questionnaire with demographic information of the students and the Augmented Reality Applications Attitude Scale (ARAAS) developed by Küçük, Yılmaz, Baydaş and Göktaş (2014). It was attempted to obtain information about the attitudes of the students regarding the AR applications before the application. After carrying out the study, by allowing the students to fill the Augmented Reality Applications Attitude Scale again, it was aimed to observe whether there was a difference in their attitudes towards the AR applications. At the end of the study, the participants were given questions through a semi-structured interview form. Their opinions on the use of the AR applications in educational settings were taken. Four weeks after the study, the participants were asked to fill in the Augmented Reality Applications Attitude Scale again to measure the persistence effect of the attitude on the participants.

Table 1: Experimental Design Applied in the Research

\begin{tabular}{|c|c|c|c|c|}
\hline & Pretest & Processing & $\begin{array}{c}\text { Final } \\
\text { Test }\end{array}$ & $\begin{array}{c}\text { Retention } \\
\text { Test }\end{array}$ \\
\hline R & ARAAS & AR Application & ARAAS & ARAAS \\
\hline
\end{tabular}




\section{Study Group}

The sample determined for the study consists of 33 students studying in the Computer Engineering Program of the Engineering Faculty of Istanbul Rumeli University in the spring semester of the 20192020 academic year. Demographic information for the participants is given in Table 2 .

Table 2: Demographic Information of Participants Variable

\begin{tabular}{|l|l|c|c|}
\hline Variable & \multicolumn{1}{|c|}{ Group } & N & \% \\
\hline \multirow{4}{*}{ Gender } & Male & 27 & 81.8 \\
\cline { 2 - 4 } & Female & 6 & 18.2 \\
\hline \multirow{4}{*}{ Class } & Class 1 & 15 & 45.5 \\
\cline { 2 - 4 } & Class 2 & 10 & 30.3 \\
\cline { 2 - 4 } & Class 3 & 8 & 24.2 \\
\hline \multirow{3}{*}{$\begin{array}{l}\text { Daily Internet } \\
\text { usage }\end{array}$} & $1-4$ hours & 16 & 48.5 \\
\cline { 2 - 4 } & 5-6 hours & 6 & 18.2 \\
\cline { 2 - 4 } & 7 hours and over & 11 & 33.3 \\
\hline $\begin{array}{l}\text { Most preferred } \\
\text { device type for }\end{array}$ & Mobile devices & 18 & 54.5 \\
\cline { 2 - 4 } Internet use & Computer & 15 & 45.5 \\
\hline \multirow{3}{*}{$\begin{array}{l}\text { Internet usage } \\
\text { purpose }\end{array}$} & Reading - Research & 6 & 18.2 \\
\cline { 2 - 4 } & Social networks - Chat & 19 & 57.6 \\
\cline { 2 - 4 } & Game - Movie & 8 & 24.2 \\
\hline \multirow{3}{*}{$\begin{array}{l}\text { Father's } \\
\text { Education } \\
\text { Level }\end{array}$} & Primary school & 2 & 27.3 \\
\cline { 2 - 4 } & Middle School & 9 & 18.2 \\
\cline { 2 - 4 } & High school & 18 & 33.3 \\
\cline { 2 - 4 } & University and Master & 4 & 9.1 \\
\hline \multirow{3}{*}{$\begin{array}{l}\text { Mother's } \\
\text { Education }\end{array}$} & Primary school & 14 & 42.4 \\
\cline { 2 - 4 } Level & Middle School & 8 & 24.2 \\
\cline { 2 - 4 } & High school & 8 & 24.2 \\
\cline { 2 - 4 } & University and Master & 3 & 9.1 \\
\hline
\end{tabular}

\section{Data Collection Tools}

In the quantitative data collection process of the study, a participation questionnaire with demographic information of the students, the Augmented Reality Applications Attitude Scale to find out their attitudes to the AR applications, and a semi-structured interview form to obtain their opinions on the use of the AR applications in educational settings were used. To observe the changes in students' attitudes towards the AR applications, the Augmented Reality Applications Attitude Scale was filled by the students 3 times; before, after, and 4 weeks after the research.
Augmented Reality Applications Attitude Scale: The Augmented Reality Attitude Scale used in the study is developed by Küçük et al. (2014) and consists of 3 factors and 15 items. Of 15 items in the scale, 2 items (12 and 13) measure the Use Willingness subfactor, 6 items $(2,3,6,8,10$, and 14) the Use anxiety sub-factor, and 7 items $(1,4,5,7,9,11$ and 15) the Use Satisfaction sub-factor. The scale has a 5-Likert structure consisting of "I disagree", "I disagree", "I am ambivalent", "I agree", and "I agree" options. The scale internal consistency (Cronbach Alpha) analysis was carried out by the researchers and it was concluded that the scale is reliable. For the overall scale, it is calculated as $\alpha=0.835$; for Use Willingness Factor, it is calculated as $\alpha=.862$; for the Use anxiety Factor, it is calculated as $\alpha=.828$; and for the Use Satisfaction Factor, it is calculated as $\alpha=.644$.

The "Augmented Reality Attitude Scale" developed by Küçük et al., (2014) is intended to be used in determining secondary school students' attitudes towards the AR applications. To make use of the scale in this study, which the attitudes of the students of the Faculty of Engineering towards augmented reality applications are measured, the confirmatory factor analysis (CFA) was conducted with 266 participants attending the undergraduate education at Istanbul Rumeli University.

Considering the indices $(\chi 2=155.400, \mathrm{df}=85 \chi 2 /$ $\mathrm{df}=1.828, \mathrm{RMSEA}=.056, \mathrm{SRMR}=.038, \mathrm{GFI}=.927$, AGFI $=.897, \quad$ NFI $=.934, \quad$ CFI $=.969, \quad$ TLI $=.961$, IFI $=.969, \mathrm{p}<.001)$ for the confirmatory factor analysis (CFA) at 0.05 significance level, it can be said that the 3 -factor structure of the scale is maintained for the students studying at the University as well (Byrne, 2001; Hu \& Bentler, 1999; Schreiber, et al, 2006). The regression weights of the Use Willingness dimension, the first factor of the scale, vary between .73 and .78. In contrast, the regression weights of the Use Anxiety sub-dimension, the second factor of the scale, vary between .66 and .79 , and the regression weights of the use satisfaction sub-dimension, the third factor, vary between 0.78 and 0.82 . However, the internal consistency coefficient (Cronbach Alpha) is .86 for the first factor of the scale, .88 for the second factor, and .87 for the third factor. Furthermore, the internal consistency coefficient (Cronbach Alpha) for the overall scale was .87. 


\section{Data Analysis}

For quantitative data collected at the end of the study, normality tests, descriptive statistics, t-test, one-way ANOVA, and one-way repeated measurements, ANOVA tests were used. Content analyses were used to analyze the qualitative data collected from the participants.

After analyzing the content, an inter-coding reliability study was conducted with the support from an academician who was an expert in the field. It was revealed that the study was reliable based on the results obtained. In the study, the reliability coefficient between coders was calculated with the formula; coefficient= consensus / (consensus + dissensus). The study's reliability was calculated to be $87 \%$ and it was concluded that this result would be considered reliable (Miles \& Huberman, 1994).

\section{Findings}

\section{Analysis of Quantitative Data}

\section{Pre-Research Augmented Reality Attitude Change Analysis}

Descriptive statistical values for determining students' attitudes towards augmented reality applications are given in Table 3. Prior to the descriptive analysis, the inverse questions in the use anxiety sub-factor are arranged.

As a result of the analysis, the average of students' attitude scores for augmented reality applications
$(\overline{\mathrm{X}} / \mathrm{m}=3.70)$ is above the mean. When the subdimensions of the scale are examined, it is observed that the highest average score $(\overline{\mathrm{X}} / \mathrm{m}=3.92)$ belongs to the Use Willingness sub-factor. In contrast, the lowest average score $(\overline{\mathrm{X}} / \mathrm{m}=3.61)$ belongs to the user satisfaction sub-factor.

Table 3: Descriptive Values of Augmented Reality Applications Attitude Scale

\begin{tabular}{|l|c|c|c|c|c|}
\hline \multicolumn{1}{|c|}{ Variable } & N & $\mathbf{m}$ & $\overline{\mathbf{x}}$ & $\overline{\mathbf{x}} / \mathrm{m}$ & $\mathbf{S d}$ \\
\hline The use willingness & 33 & 2 & 7.84 & 3.92 & 0.53 \\
\hline The use anxiety & 33 & 6 & 22.38 & 3.73 & 0.39 \\
\hline The use satisfaction & 33 & 7 & 25.27 & 3.61 & 0.52 \\
\hline $\begin{array}{l}\text { Augmented Reality } \\
\text { Applications } \\
\text { Attitude }\end{array}$ & 33 & 15 & 55.05 & 3.70 & 0.39 \\
\hline
\end{tabular}

$\mathrm{m}$ : Refers to the number of items.

The values indicating the difference between students' augmented reality attitudes and gender variables are presented in Table 4 . The results of the analysis show that there is no significant difference between the students' attitude scores on augmented reality applications and the gender variable $\left(\mathrm{t}_{(31)}=\right.$ $0.21, p>.05)$. Similarly, when the sub-dimensions of the scale are examined, again, it can be seen that there is no significant difference between the sub-factor attitude scores and the gender variable $(\mathrm{t}(31)=0.04$, $\left.\mathrm{p}>.05 ; \mathrm{t}_{(31)}=0.07, \mathrm{p}>.05 ; \mathrm{t}_{(31)}=-0.38, \mathrm{p}>.05\right)$.

Table 4: T-Test Results by Augmented Reality Applications Attitude Scale and Gender Variable

\begin{tabular}{|c|c|c|c|c|c|c|c|}
\hline Variable & Group & $\mathbf{N}$ & $\overline{\mathbf{x}}$ & Sd & df & $\mathbf{t}$ & $\mathbf{p}$ \\
\hline \multirow{2}{*}{ The use willingness } & Male & 27 & 7.85 & 1.13 & \multirow{2}{*}{31} & \multirow{2}{*}{.038} & \multirow{2}{*}{.97} \\
\hline & Female & 6 & 7.83 & .75 & & & \\
\hline \multirow{2}{*}{ The use anxiety } & Male & 27 & 22.41 & 2.53 & \multirow{2}{*}{31} & \multirow{2}{*}{.069} & \multirow{2}{*}{.95} \\
\hline & Female & 6 & 22.33 & 1.37 & & & \\
\hline \multirow{2}{*}{ The use satisfaction } & Male & 27 & 25.19 & 3.86 & \multirow{2}{*}{31} & \multirow{2}{*}{-.384} & \multirow{2}{*}{.70} \\
\hline & Female & 6 & 25.83 & 2.99 & & & \\
\hline \multirow{2}{*}{ Augmented Reality Applications Attitude } & Male & 27 & 55.44 & 6.25 & \multirow{2}{*}{31} & \multirow{2}{*}{-.207} & \multirow{2}{*}{.84} \\
\hline & Female & 6 & 56.00 & 4.10 & & & \\
\hline
\end{tabular}

The values indicating the relation between students' augmented reality attitudes and class variables are presented in Table 5. The results of the analysis show that the difference between the students' attitude scores on augmented reality applications and the class variable is not significant $\left(\mathrm{F}_{(2-30)}=2.09, \mathrm{p}>.05\right)$. Similarly, when the subdimensions of the scale are examined, it can be seen that the difference is not significant. 
Table 5: ANOVA Results of Augmented Reality Applications Attitude Scale by Class Variable

\begin{tabular}{|c|l|c|c|c|c|c|}
\hline Variable & Source of Variance & Sum of Squares & $\mathbf{d f}$ & Mean Square & F & $\mathbf{p}$ \\
\hline \multirow{4}{*}{ The use willingness } & Between groups & 1.47 & 2 & .73 & 2.90 & .07 \\
\hline & Within groups & 7.59 & 30 & .25 & & \\
\hline & Total & 9.06 & 32 & & & \\
\hline \multirow{4}{*}{ The use anxiety } & Between groups & .21 & 2 & .11 & .68 & .52 \\
\cline { 2 - 7 } & Within groups & 4.68 & 30 & .16 & & \\
\hline & Total & 4.89 & 32 & & & \\
\hline \multirow{4}{*}{ The use satisfaction } & Between groups & 1.03 & 2 & .52 & 1.97 & .16 \\
\hline & Within groups & 7.85 & 30 & .26 & & \\
\hline & Total & 8.88 & 32 & & & \\
\hline \multirow{2}{*}{$\begin{array}{c}\text { Augmented Reality } \\
\text { Applications Attitude }\end{array}$} & Between groups & .60 & 2 & .30 & 2.09 & .14 \\
\hline & Within groups & 4.30 & 30 & .14 & & \\
\hline & Total & 4.90 & 32 & .73 & & \\
\hline
\end{tabular}

The values indicating the difference between students' augmented reality attitudes and daily internet usage duration variables are presented in Table 6 . When the values are examined, it can be seen that the difference between the augmented reality attitude and the daily internet usage duration variable is not significant $\left(\mathrm{F}_{(2-30)}=1.30, \mathrm{p}>.05\right)$. However, when the sub-factors of scale are examined, it is observed that the difference between the Use Satisfaction sub-factor and the daily internet usage duration variable is significant $\left(\mathrm{F}_{(2-30)}=3.64, \mathrm{p}<.05\right)$. When the results of the LSD test, conducted to determine the significance of the difference between the groups, it was concluded that the difference between the participants, who states that their daily Internet usage duration is 5-6 hours ( $\overline{\mathrm{X}}=3.92)$, and the participants, who state that their daily Internet usage time is 7 hours and above $(\overline{\mathrm{X}}=3.31)$, is significant.

Table 6: ANOVA Results of Augmented Reality Applications Attitude Scale by Daily Internet usage Variable

\begin{tabular}{|c|c|c|c|c|c|c|c|}
\hline Variable & Source of Variance & Sum of Squares & df & Mean Square & $\mathbf{F}$ & $\mathbf{p}$ & Sig. Diff. \\
\hline \multirow{3}{*}{ The use willingness } & Between groups & .04 & 2 & .02 & .070 & .93 & \\
\hline & Within groups & 9.02 & 30 & .30 & & & \\
\hline & Total & 9.06 & 32 & & & & \\
\hline \multirow{3}{*}{ The use anxiety } & Between groups & .10 & 2 & .05 & .310 & .74 & \\
\hline & Within groups & 4.79 & 30 & .16 & & & \\
\hline & Total & 4.89 & 32 & & & & \\
\hline \multirow{3}{*}{ The use satisfaction } & Between groups & 1.73 & 2 & .87 & 3.64 & .04 & $2-3$ \\
\hline & Within groups & 7.14 & 30 & .24 & & & \\
\hline & Total & 8.88 & 32 & & & & \\
\hline \multirow{3}{*}{$\begin{array}{l}\text { Augmented Reality } \\
\text { Applications } \\
\text { Attitude }\end{array}$} & Between groups & .39 & 2 & .20 & 1.30 & .29 & \\
\hline & Within groups & 4.51 & 30 & .15 & & & \\
\hline & Total & 4.90 & 32 & & & & \\
\hline
\end{tabular}

The values indicating the possible significant difference between the students' attitudes to augmented reality and their parents' educational status are included in Table 7 and Table 8. In this context, the educational status of the parents of the students was evaluated separately.

Analysis results (Table 7) indicate that there was no significant difference between students' attitude scores on augmented reality applications and the education status of their fathers $\left(\mathrm{F}_{(3-29)}=0.44, \mathrm{p}>.05\right)$. 
Table 7: Anova Results of Augmented Reality Applications Attitude Scale According to Father's Education Status

\begin{tabular}{|l|l|c|c|c|c|c|}
\hline \multicolumn{1}{|c|}{ Variable } & Source of Variance & Sum of Squares & df & Mean Square & F & p \\
\hline \multirow{4}{*}{ The use willingness } & Between groups & .27 & 3 & .09 & .29 & .83 \\
\cline { 2 - 7 } & Within groups & 8.79 & 29 & .30 & & \\
\cline { 2 - 7 } & Total & 9.06 & 32 & & & \\
\hline \multirow{4}{*}{ The use anxiety } & Between groups & .31 & 3 & .10 & .66 & .58 \\
\cline { 2 - 8 } & Within groups & 4.57 & 29 & .16 & & \\
\cline { 2 - 7 } & Total & 4.89 & 32 & & & \\
\hline \multirow{4}{*}{$\begin{array}{l}\text { Tugme use satisfaction } \\
\text { Applications Attitude }\end{array}$} & Between groups & .50 & 3 & .17 & .58 & .64 \\
\hline & Within groups & 8.38 & 29 & .29 & & \\
\hline & Total & 8.88 & 32 & & & \\
\hline & Wetween groups & .21 & 3 & .07 & .44 & .73 \\
\hline & Within groups & 4.69 & 29 & .16 & & \\
\hline
\end{tabular}

It is seen in Table 8 that there was no significant difference between students' attitude scores on augmented reality applications and the education status of their mothers $\left(\mathrm{F}_{(3-29)}=2.22, \mathrm{p}>.05\right)$. However, when the sub-factors of the attitude scale are examined, it is observed that there is a significant difference between the Use anxiety subfactor scores and the educational status of the mother $\left(\mathrm{F}_{(3-29)}=3.15, \mathrm{p}<.05\right)$. The results of the LSD test conducted to determine between which groups there is a significant difference, it is possible to conclude that there is a significant difference between the participants who states that the educational status of their mothers is an elementary school $(\overline{\mathrm{X}}=3.67)$, middle school $(\overline{\mathrm{X}}=3.68)$, and high school $(\overline{\mathrm{X}}=3.64)$, and the participants who state that their education is undergraduate and graduate $(\overline{\mathrm{X}}=4.33)$.

Table 8: ANOVA Results of Augmented Reality Applications Attitude Scale by

Mother's Education Status Variable

\begin{tabular}{|c|c|c|c|c|c|c|c|}
\hline Variable & Source of Variance & Sum of Squares & df & Mean Square & $\mathbf{F}$ & p & Sig. Diff. \\
\hline \multirow{3}{*}{ The use willingness } & Between groups & 1.00 & 3 & .33 & 1.20 & .33 & \\
\hline & Within groups & 8.06 & 29 & .28 & & & \\
\hline & Total & 9.06 & 32 & & & & \\
\hline \multirow{3}{*}{ The use anxiety } & Between groups & 1.20 & 3 & .40 & 3.15 & .04 & $1-4$ \\
\hline & Within groups & 3.69 & 29 & .13 & & & $2-4$ \\
\hline & Total & 4.89 & 32 & & & & $3-4$ \\
\hline \multirow{3}{*}{ The use satisfaction } & Between groups & 1.13 & 3 & .38 & 1.41 & .26 & \\
\hline & Within groups & 7.75 & 29 & .27 & & & \\
\hline & Total & 8.88 & 32 & & & & \\
\hline \multirow{3}{*}{$\begin{array}{l}\text { Augmented Reality } \\
\text { Applications Attitude }\end{array}$} & Between groups & .91 & 3 & .31 & 2.22 & .11 & \\
\hline & Within groups & 3.99 & 29 & .14 & & & \\
\hline & Total & 4.90 & 32 & & & & \\
\hline
\end{tabular}

Pre-Research and Post-Research Augmented Reality Attitude Change Analysis

The values indicating the difference between the pre-research attitude scores of the students in the study towards the augmented reality applications and their post-research attitude scores towards the augmented reality applications are shown in Table 9. 
As a result of the analysis, it can be seen that there is a significant difference between the students' preresearch and post-research attitude scores towards augmented reality $\left(\mathrm{t}_{(33)}=-4.44, \mathrm{p}<.05\right)$. It is observed that the post-research attitude scores of the students towards the augmented reality were higher than their pre-research attitude scores; in other words, that the attitudes of the students towards the augmented reality changed positively. Similarly, when the subfactors related to the augmented reality attitudes of the students are examined, it can be seen that there is a significant difference between the Use Satisfaction, The use anxiety and Use Willingness attitude scores $\left(\mathrm{t}_{(33)}=-2.48, \mathrm{p}<.05 ; \mathrm{t}_{(33)}=-4.37, \mathrm{p}<.05 ; \mathrm{t}_{(33)}=-4.13\right.$, $\mathrm{p}<.05)$.

Table 9: Related Groups t-Test Results on Students' Attitudes of Augmented Reality Applications Variable

\begin{tabular}{|l|c|c|c|c|c|c|}
\hline \multicolumn{1}{|c|}{ Variable } & Group & $\overline{\mathbf{x}}$ & Sd & $\mathbf{d f}$ & $\mathbf{t}$ & $\mathbf{p}$ \\
\hline \multirow{2}{*}{ The use willingness } & Before & 7.85 & 1.06 & \multirow{2}{*}{33} & \multirow{2}{*}{-2.48} & \multirow{2}{*}{.02} \\
\cline { 2 - 5 } & After & 8.70 & 1.65 & & & \\
\hline \multirow{2}{*}{ The use anxiety } & Before & 22.39 & 2.34 & \multirow{2}{*}{33} & -4.37 & \multirow{2}{*}{.00} \\
\cline { 2 - 5 } & After & 25.42 & 3.22 & & & \\
\hline \multirow{2}{*}{ The use satisfaction } & Before & 25.30 & 3.69 & \multirow{2}{*}{33} & \multirow{2}{*}{00} \\
\cline { 2 - 5 } & After & 29.61 & 4.72 & & \\
\hline \multirow{2}{*}{ Augmented Reality Applications Attitude } & Before & 55.55 & 5.87 & \multirow{2}{*}{-4.44} & \multirow{2}{*}{.00} \\
\cline { 2 - 5 } & After & 63.73 & 8.83 & & & \\
\hline
\end{tabular}

Pre-Research, Post-Research, and Persistence Augmented Reality Attitude Change Analysis

To determine the students' attitudes towards augmented reality applications and the level of the permanence of the study, the augmented reality applications attitude scale was applied three times; before, after, and four weeks after the research (Table 10).

As a result of the analysis of the pre-research augmented reality attitude scale, it is observed that the average of students' attitude scores $(\overline{\mathrm{X}} / \mathrm{m}=3.70)$ are above the mean. When the sub-dimensions of the scale are examined, it is observed that the highest average score $(\overline{\mathrm{X}} / \mathrm{m}=3.92)$ belongs to the Use Willingness sub-factor. In contrast, the lowest average score $(\overline{\mathrm{X}} / \mathrm{m}=3.61)$ belongs to the Use Satisfaction sub-factor.

As a result of the post-research augmented reality attitude scale analysis, an increase in students' attitude scores $(\overline{\mathrm{X}} / \mathrm{m}=4.24)$ is observed compared to their pre-research attitude scores. Similarly, when the sub-dimensions of the scale are examined, it can be seen that there is an increase in the Use Willingness $(\overline{\mathrm{X}} / \mathrm{m}=4.34)$ and the Use Satisfaction $(\overline{\mathrm{X}} / \mathrm{m}=4.22)$ sub-factors. When the Use anxiety sub-factor is examined, it is observed that there is decrease in post-research anxiety scores of students $(\overline{\mathrm{X}} / \mathrm{m}=4.23)$.

Four weeks after the study, the augmented reality attitude scale was re-applied to determine the persistence status of the research on the participants. As a result of the analysis, it is observed that the students' augmented reality attitude score averages are higher than the pre-application attitude score average but lower than the post-application attitude score average. Similarly, in the measurement related to the persistence test, when the sub-factors of the scale are examined, it can also be seen that they are higher than the pre-research attitude scores but lower than the post-research attitude scores.

Table 10: Pre-study, post-study and 4 weeks after the study Augmented Reality Applications Attitude Scale Descriptive Statistics

\begin{tabular}{|l|c|c|c|c|c|}
\hline \multicolumn{1}{|c|}{ Variable } & $\mathbf{N}$ & $\mathbf{m}$ & $\overline{\mathbf{x}}$ & $\overline{\mathbf{x}} / \mathbf{M}$ & $\mathbf{S d}$ \\
\hline Before the study & & & & & \\
\hline The use willingness & 33 & 2 & 7.84 & 3.92 & 0.53 \\
\hline
\end{tabular}




\begin{tabular}{|l|c|c|c|c|c|}
\hline The use anxiety & 33 & 6 & 22.38 & 3.73 & 0.39 \\
\hline The use satisfaction & 33 & 7 & 25.27 & 3.61 & 0.52 \\
\hline Augmented Reality Applications Attitude & 33 & 15 & 55.05 & 3.70 & 0.39 \\
\hline After the study & & & & & \\
\hline The use willingness & 33 & 2 & 8.68 & 4.34 & 0.82 \\
\hline The use anxiety & 33 & 6 & 25.42 & 4.23 & 0.53 \\
\hline The use satisfaction & 33 & 7 & 29.54 & 4.22 & 0.67 \\
\hline Augmented Reality Applications Attitude & 33 & 15 & 63.60 & 4.24 & 0.58 \\
\hline 4 weeks after the study & & & & & \\
\hline The use willingness & 33 & 2 & 8.68 & 4.19 & 0.33 \\
\hline The use anxiety & 33 & 6 & 23.34 & 3.59 & 0.54 \\
\hline The use satisfaction & 33 & 7 & 29.68 & 3.99 & 0.38 \\
\hline Augmented Reality Applications Attitude & 33 & 15 & 61.65 & 3.86 & 0.38 \\
\hline
\end{tabular}

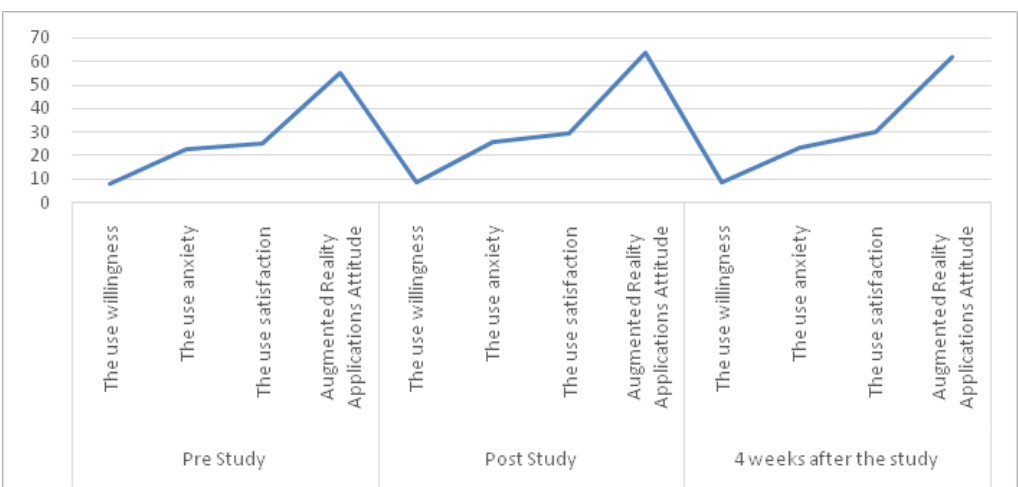

\section{Figure 2: Descriptive Statistics of Augmented Reality Applications Attitude Scale Pre-Study, Post Study and 4 Weeks After Study}

The values indicating the difference between the students' attitude scores towards augmented reality before, after and 4 weeks after the application are shown in Table 11. According to the findings, there is a significant difference between attitude scores before, after, and four weeks after the application $\left(\mathrm{F}_{(2,64)}=24.80, \quad \mathrm{p}<0.05, \quad \eta^{2}=.437\right)$. According to Büyüköztürk (2010), $\eta^{2}$ values indicate a small effect size between .01 and .06 , medium effect size between $.06-.14$, and large effect size above .14. Considering the value $\eta 2$, the resulting value for measurementtime interaction describes $44 \%$ of the variance.
The Bonferroni test was used to determine the significant difference between the augmented reality attitude scores is in between which measurements. The findings obtained has revealed a significant difference between the pre-research attitude score average and post-research attitude score average at the level of $\mathrm{p}=0.001$, between the pre-research attitude score average and the attitude score average four weeks later at the level of $\mathrm{p}=0.004$, and between the post-research attitude score and the attitude score after four weeks at the level of $p=0.001$.

Table 11: One-Way Repeated Measures of Augmented Reality Applications Attitude Scale According to Time ANOVA Results

\begin{tabular}{|c|c|c|c|c|c|c|c|}
\hline Source of Variance & Sum of Squares & $\mathbf{d f}$ & Mean Square & $\mathbf{F}$ & $\mathbf{p}$ & $\boldsymbol{\eta}^{\mathbf{2}}$ & Sig. Diff. \\
\hline Between Subjects & 2887.84 & 32 & 90.25 & & & & $1-2$, \\
\hline Between Measures & $\mathbf{1 1 6 7 . 9 0}$ & $\mathbf{2}$ & $\mathbf{8 6 3 . 1 9}$ & $\mathbf{2 4 . 8 0}$ & $\mathbf{. 0 0 1}$ & $\mathbf{0 . 4 4}$ & $1-3$, \\
\hline
\end{tabular}




\begin{tabular}{|c|c|c|c|c|c|c|c|}
\hline Error & 1506.77 & 64 & 34.80 & & & & $2-3$ \\
\hline Total & 5562.51 & 96 & & & & & \\
\hline
\end{tabular}

The chart related to the pre-application, postapplication and persistence Augmented Reality Applications Attitude Scale score averages is given in Figure 3. As it is clear from the chart that it is observed that the students' post-research augmented reality attitude scores are higher than their preresearch and the attitude scores 4 weeks after the research. There is a significant difference between them.

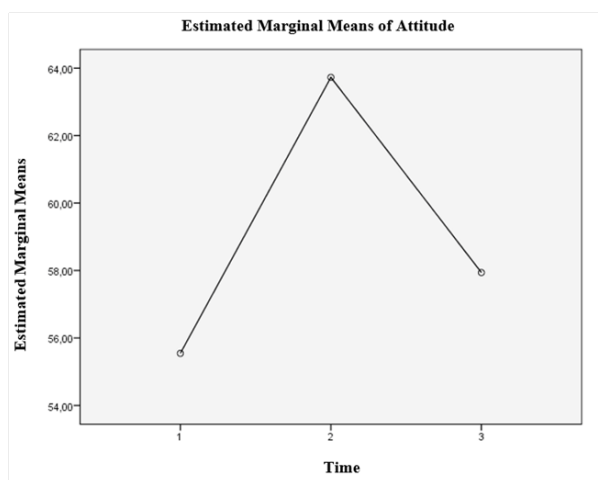

Figure 3: One-Way Repeated Measures ANOVA Results Graph of Augmented Reality Applications Attitude Scale Averages According to Time

\section{Analysis of Quantitative Data}

33 computer engineering students who participated in the research were given a semistructured interview form at the end of the research. Data were collected by asking questions about the AR applications and the research performed.

The questions asked to the participants via the interview form are as follows:

1. Did you have any prior knowledge of the AR applications?

2. What do you think about the developed AR application?

3. How do you think the use of AR applications in courses will benefit you?

4. How can supporting your courses with the AR applications help your instructors?

5. Do the AR applications contribute to the time spent learning a subject?

http://www.shanlaxjournals.com
6. What courses do you think the AR applications will be most useful?

7. Did you experience any difficulty while using the developed AR application?

The data of the answers given by the students to the questions in the form are presented below.

\section{Did we have any prior knowledge of the AR applications?}

The answers given by the students to the question asked to determine whether the students have any prior knowledge about the AR technologies and applications are collected under 3 different themes and these themes are presented in Table 12. 13 participants in the study stated that they had previous knowledge about the AR applications, 18 participants stated that they had no previous knowledge, and 2 participants stated that they had partial knowledge.

STUDENT3 expressed this opinion with the words "It is used in the gaming world and social media applications", STUDENT5, on the other hand, expressed it as "I have carried out a research and played Pokemon Go". STUDENT22, who answered the question by saying, "No, I do not know", expressed his/her opinion "I have not heard about it, I obtained information thanks to this study". STUDENT12 expressed his/her opinion by saying that "I thought it was something like virtual reality."

\section{Table 12: Did we know about $A R$ applications} before?

\begin{tabular}{|l|l|}
\hline \multicolumn{1}{|c|}{ Opinion } & f \\
\hline Yes, I had the information & 13 \\
\hline No, I did not know & 18 \\
\hline I have some information & 2 \\
\hline
\end{tabular}

What do you think about the developed AR application?

The answers given by the students to the question asked to determine the views of the students about the AR application are summarized under 3 different themes, and these themes are presented in Table 13. While the participants did not express any negative opinion about the application developed, 
20 participants stated that they found the application remarkable; 13 participants stated that they found it visually successful and understandable, and 9 participants found it enjoyable.

While STUDENT19, who stated that he found the developed AG application remarkable, expressed his opinion as "It enabled me to increase my interest in the course, I find it useful", STUDENT16, who stated that he/she found it visually successful and understandable, expressed his opinion as "It makes the subject easier to understand, I think that visualization of knowledge makes learning more permanent". STUDENT24, who stated that the developed AG application is amusing, expressed his opinion by saying that "It provides an extraordinary experience, enjoyable and easy learning".

Table 13: What do you think about the developed AR application?

\begin{tabular}{|l|c|}
\hline \multicolumn{1}{|c|}{ Opinion } & f \\
\hline A remarkable application & 20 \\
\hline $\begin{array}{l}\text { Visuals are a successful and } \\
\text { understandable application }\end{array}$ & 13 \\
\hline Fun app & 9 \\
\hline
\end{tabular}

\section{How do you think the use of the AR applications} in courses will benefit you?

The answers given by the students to the question asked to determine the opinions of the students about the AR application are summarized under 5 different themes and presented in Table 14. 13 of the participants stated that the developed application would make the course content more visual. In contrast, 8 participants stated that it would enable better understanding, and 5 participants stated that the application would increase the attention to the course. 3 participants stated that the AR applications would make the student more active. In comparison, 4 participants stated that the AR applications would enable better learning than the absence of the AR applications.

STUDENT32, who states that the AR application makes the learning process more active, expresses his opinion by stating that "I felt that I was more actively involved in the learning process by moving the experiments that we could not perform in the classroom to the virtual environment." STUDENT13, who states that the AR will make learning faster, expressed his opinion with the sentence that "It will provide better learning that will increase the memorability of the course". STUDENT 8, who states that the attention to the course increased, expressed his opinion with the words that "It attracted my attention and interest.So, I listened to the course with more attention and interest than I ever listened to it." STUDENT29, who states that the AR applications would provide visual effects, expressed that "I can more easily imagine many things that are abstract via the AR". STUDENT26, another participant, expressed his/her opinion by saying that "This application enables students to shape the subject more quickly in their minds" and emphasized that he/she would express its impact on the learning process.

Table 14: How do you think it would be beneficial to use AR applications in lessons?

\begin{tabular}{|l|c|}
\hline \multicolumn{1}{|c|}{ Opinion } & f \\
\hline Makes the student active & 3 \\
\hline Provides better understanding & 8 \\
\hline Provides attention & 5 \\
\hline Makes the content more visual & 13 \\
\hline Provides fast learning & 4 \\
\hline
\end{tabular}

How can supporting your courses with the AR applications help your instructors?

The answers given by the students to the question asked to determine the opinions of the students about how the use of AG applications can be beneficial for the instructors in the courses are summarized under 4 different themes and presented in Table 15. To answer this question, 16 of the students expressed their opinion that it would make easier to attract the attention of the student, 13 of them by saying that it would increase the student's participation in the course, 9 of them by saying that the interest in the course would increase, while 5 of them by saying that my respect for the course instructor increases.

STUDENT23, who explains how the AG applications can be useful for instructors in the courses, expresses his opinion by saying that "With the increasing attention of the student, the instructor, I think, will save time and effort". In contrast, STUDENT22 expresses his opinion by saying that 
"It can facilitate the narration and they can quickly explain the concepts that may be difficult to express using simple 3-D visuals". STUDENT28, who states that his/her respect for the instructor increases, expressed his opinion by saying that "The fact that the instructor comes to the class with the applications that will help us learn more easily ensures that my respect for his/her field expertise increases".

Table 15: Is there any benefit for instructors to support the courses with AR applications?

\begin{tabular}{|l|c|}
\hline \multicolumn{1}{|c|}{ Opinion } & f \\
\hline Makes it easier to gather attention & 16 \\
\hline Increases participation in class & 13 \\
\hline Interest in the lesson increases & 9 \\
\hline My respect for the instructor increases & 5 \\
\hline
\end{tabular}

Do the AR applications contribute to the time spent learning a subject?

The answers given by the students to the question asked to determine the effect of the AR application on learning the subject are summarized in 2 different themes and presented in Table 16.

A significant majority of participants, 30 participants, states that the AR applications would shorten the learning time, while 3 participants stated that these applications would cause loss of time.

While STUDENT33, who expresses his/her opinion that it will accelerate learning, expresses his/her opinion by saying that "It will be useful in terms of time, it can be considered a fast learning", STUDENT26, who states that it will cause loss of time, expresses his/her opinion that "Dealing with 3D objects like games will distract me and cause that the time I spend on learning the course will increase".

Table 16: Do AR applications contribute to the time spent learning a subject?

\begin{tabular}{|l|c|}
\hline \multicolumn{1}{|c|}{ Opinion } & f \\
\hline Shortening the learning time & 30 \\
\hline Don't waste time & 3 \\
\hline
\end{tabular}

What courses do you think the AR applications will be most useful?

The answers given by the students to the question asked to the participants to determine the type of course that the AR applications will benefit the most if used in educational settings are summarized in 3 different themes and presented in Table 17. 22 participants stated that the AR applications will benefit in all courses. Twelve participants stated that it would be useful to use it in practical courses and 7 participants in social courses.

STUDENT18, who stated that the AR applications would be useful for all courses, expressed his opinion by saying that "the AR can be used for every course and provides effective learning". While STUDENT25, who stated that it would be more useful in social lessons, expressed his/her opinion by saying that "the AR may be more useful with visuals used in geography and history lessons", STUDENT15, who stated that the AR would be more useful in practical lessons, expressed his/her opinion by saying that "I think it would be more useful in the courses where we study on graphs or in the courses dealing with the subjects that we can see around us physically".

Table 17: In which lessons do you think AR applications will be most useful?

\begin{tabular}{|l|c|}
\hline \multicolumn{1}{|c|}{ Opinion } & f \\
\hline In social lessons & 7 \\
\hline In practical lessons & 12 \\
\hline In all classes & 22 \\
\hline
\end{tabular}

Did you experience any difficulty while using the developed AR application?

The answers given by the students to the question asked to the participants to determine whether there is a difficulty during the use of the developed AR application are summarized in 2 different themes and specified in Table 18. 26 of the students stated that they had no difficulty in using the application. In contrast, 7 participants stated that they had difficulty.

STUDENT11, who stated that he had difficulty in using the developed AG application, expressed his/her opinion by saying that "I had difficulty in the beginning because it was an application that I was not used to, but I got used to it in a short time". STUDENT26, who stated that he/she did not experience any difficulties, expressed his opinion by saying that "No, I had no difficulties, I am good with technology". 
Table 18: Did you have any difficulties while using the developed AR application?

\begin{tabular}{|l|c|}
\hline \multicolumn{1}{|c|}{ Opinion } & f \\
\hline Yes, I had & 7 \\
\hline No, I didn't have & 26 \\
\hline
\end{tabular}

\section{Discussion and Conclusion}

In this study, an attitude scale was applied in order to determine the pre-application attitudes of students regarding the AR applications. When the scale results were examined, it was observed that students' attitude scores were above the mean. When the sub-factors of the scale were examined, it is also observed that the scores of the Use Anxiety, the Use Willingness, and the Use Satisfaction factors are above the mean. From that point, it can be concluded that the students are very keen to use the AR applications. This finding is similar to the findings seen in the literature (Delello, 2014; Eroğulu, 2018; Karal \& Abdüsselam, 2015; Yusoff \& Dahlan, 2013;). The fact that the scores of attitudes towards the AR applications are above the mean can be explained in the studies conducted by Cai (2013), Yusoff and Dahlan (2013) that the AR applications have a remarkable effect on the students.

In the study, it is observed that there was no significant difference between the average attitude score of the students towards the AR applications and the gender variable, the AR attitude scores of the male students, however, are higher than those of the female students. The average attitude score of the male students, again, is higher than the average of the female students in the Use Willingness and the Use Anxiety sub-factors. On the other hand, the average attitude score of female students was higher than that of male students in the Use Satisfaction sub-factor. These findings are similar to those of the literature (Ersoy, et al, 2016; Kara, 2018; Özabac1 \& Olgun, 2011; Y1lmaz, 2014).

It is observed in the study that there is no significant difference between the average score of attitudes towards the AR applications and the class variable. However, when the scale sub-factors are examined, it is observed that there is a significant difference between the Use Willingness sub-factor and the class variable. In support of this finding, all participants, regardless of their class, found that the
AR applications are educational and motivating in learning in the interviews with the participants.

In the study, it was observed that there was no significant difference between the average scores of the attitudes towards the AR applications and the education status of the father. However, there appears to be a significant difference between the average score of the attitudes towards the AR applications and the educational status of the mother. It is observed that the average score of the attitudes in the Use Anxiety sub-factor is higher for the students whose mother's educational status is undergraduate and graduate than for those whose mother's educational status is elementary, middle, and high school. These findings are similar to the results of some of the studies in the literature that have been carried out. Supporting the finding, Gür (2017) states that parents have an impact on children's use of technology, while Erten (2019) points out that the increase in education levels of the parents has a positive effect on children's use of technology. Likewise, the study conducted by Toraman and Usta (2018) supports this finding of the research.

The AR attitude scale was re-applied in order to compare the pre-research average score of the attitudes of the students towards the AR applications with their post-research average score. When the findings were examined, it is observed that there is a significant difference between the two measurement averages. When the data is examined, it is observed that the attitude scores, which are above the mean before the study, increased after the application and a positive increase in students' attitudes towards the AR applications is formed. Likewise, when the scale sub-factors were examined, the increase in the averages related to the Use Willingness, the Use Satisfaction, and the Use Anxiety sub-factors is also observed. In literature review also showed that the AR studies have a positive impact on students' attitudes towards the AR applications (İzgi Onbaş1l1, 2018; Özarslan, 2013; Sirakaya, 2015; Şahin, 2017; Taşkıran, et al, 2015). On the other hand, the positive change in the students' attitudes has also appeared in the interviews made with the students. The students who participated in the application stated that they found the AR applications remarkable, amusing and understandable because of its visual materials. These 
findings are similar to the studies in the literature. In another study conducted by Gün (2014), it is stated that the AR applications are described as enjoyable and remarkable by the participants. The students stated that the use of the AR applications in educational settings would be beneficial for the instructor. It is also observed in the literature review that an enriched and visualized learning environment allows that learning can be carried out more quickly and this can be interpreted as a positive effect for the instructors (Babur, 2016; Salonen \& Sääski, 2008). Students state that using AR applications in courses will bring benefits such as visualization, ensuring fast and active learning, being remarkable, and increase the success. Likewise, in the literature review, it is observed that the AR applications facilitate learning with the effects of increasing motivation, increasing attention, creating an active learning process, embodying, and increase academic achievement (Ateş, 2018; et al, 2018; Erbaş, 2016; Eroğlu, 2018; Ersoy, Duman, \& Öncü, 2016; Güngördü, 2018; Özbek, 2018; Şahin, 2017; Tosik Gün \& Atasoy, 2017). Also, most of the students' state that the AR applications should be used in all courses and that the courses should be supported by the AG applications. As a matter of fact, this opinion of the participants is revealed in the re-implementation of the Augmented Reality Applications Attitude Scale 4 weeks after the application. The results obtained indicate that post-research attitude scores and the attitude scores 4 weeks after the research are higher than pre-research attitude scores, and that there is a significant difference between them. In other words, this finding indicates that the training carried out using the AR application causes that the attitudes of the students towards the AR applications change in a positive way on a permanent basis.

A large majority of the students involved in the study come to a common understanding that the AR applications are an applicable technology in all courses and course subjects. On the other hand, it is also observed that students are very keen on the integration of the AR applications into educational environments, as the AR applications make lessons more enjoyable and interesting. In addition, preand post-application measurements indicate that the AR applications can have a positive effect on the students' attitudes about the AR. Likewise, the AR applications are a very useful technology for distance education processes, which are more and more preferred by many universities, and therefore, the place of the AR technologies in education processes will be very important in the future. Therefore, there is a need to develop various AR applications to be used in different courses and for teaching different subjects. The need for technical information for the AR applications development processes is the biggest challenge in increasing the number of the AR applications in different fields and course subjects. In this context, creating the settings where the developers and trainers can work together will be useful in overcoming this challenge. 1st, 2nd and 3rd year undergraduates were included in this study. However, it would be useful to carry out a study with a sample group from all undergraduate classes. In the research, when both sub-factors of the post-research attitude test and the persistence test performed four weeks after the research are examined, an increase in the Use Anxiety subfactor is observed as it is case across the scale. A new study is needed to better understand the cause of the increase in the Use Anxiety sub-factor. This study aimed at the subject "Logical Circuit Design". However, it is also observed in literature that a large number of AR applications are needed, especially in the field of engineering.

\section{References}

Ateş, Ali. 7th Grade Science and Technology Course "Structure of the Substance and Pure Substances" on Augmented Reality Created using Technology Learning Material Effect on Academic Achievement, Niğde Ömer Halisdemir University, 2018.

Azuma, Ronald T. "A survey of Augmented Reality." Presence-Teleoperators and Virtual Environments, vol. 6, no. 4, 1997, pp. 355-385.

Babur, A. The Effects of using of Augmented Reality, Simulation and Real Object on Learning Achievements, Motivation and Psychomotor Performance, 2016.

Bai, Zhen, et al. "Through the Looking Glass: Pretend Play for Children with Autism." 
IEEE International Symposium on Mixed and Augmented Reality, University of South Australia, 2013.

Bimber, Oliver, and Ramesh Raskar. Spatial Augmented Reality: Merging Real and Virtual Worlds, AK Peters/CRC Press, 2005.

Bujak, Keith R., et al. "A Psychological Perspective on Augmented Reality in the Mathematics Classroom." Computers \& Education, vol. 68, 2013, pp. 536-544.

Buluş Kırıkkaya, E., and Melek Şentük. "The Impact of Using Augmented Reality Technology in the Solar System and Beyond Unit on the Academic Achievement of the Students." Kastamonu Education Journal, vol. 26, no. 1, 2018, pp. 181-189.

Byrne, Barbara M. Structural Equation Modeling with AMOS: Basic Concepts, Applications, and Programming, Routledge, 2010.

Cheng, Kun-Hung, and Chin-Chung Tsai. "Affordances of Augmented Reality in Science Learning: Suggestions for Future Research." Journal of Science Education and Technology, vol. 22, 2013, pp. 449-462.

Creswell, John W. Research Design: Qualitative, Quantitative, and Mixed Methods Approaches, Sage, 2013.

Delello, Julie A. "Insights from Pre-Service Teachers using Science-Based Augmented Reality." Journal of Computers in Education, vol. 1, 2014, pp. 295-311.

Erbaş, Çağdaş. The Effects of Mobile Augmented Reality Applications on Students' Academic Achievement and Motivation, 2016.

Eroğlu, B. Evaluation of Teaching Astronomy Concept with Augmented Reality Application for Secondary Student, 2018.

Ersoy, Hasan, et al. "Motivation and Success with Augmented Reality: An Experimental Study." Journal of Instructional Technologies \& Teacher Education, vol. 5, no. 1, 2016, pp. 39-44.

Erten, Pinar. "The Attitudes of the Z Generation towards Digital Technology." Gümüşhane Üniversitesi Sosyal Bilimler Enstitüsü Elektronik Dergisi, vol. 10, no. 1, 2019, pp. 190-202.
Eursch, Andreas. "Increased Safety for Manual Tasks in the Field of Nuclear Science Using the Technology of Augmented Reality." IEEE Nuclear Science Symposium, 2007.

Fleck, Stephen, and Gilles Simon. "An Augmented Reality Environment for Astronomy Learning in Elementary Grades: an Exploratory Study." Conference on l'Interaction HommeMachine, 2013, pp. 14-22.

Fleck, Stephen, et al. "Aible: An Inquiry-Based Augmented Reality Environment for Teaching Astronomical Phenomena." IEEE International Symposium on Mixed and Augmented Reality - Media, Art, Social Science, Humanities and Design, 2014.

Gün, E. Effects of Augmented Reality Applications on Students' Spatial Abilities, 2014.

Güngördü, D. The Effect of Augmented Reality Applications of Atom Models on Secondary School Students' Achievement and Attitude, 2018.

Gür, D. Analysis of Parental Controls and Attitudes Toward the use of Information Technologies by Middle School Students in Terms of Different Variables, 2017.

Hsiao, Kuei-Fang, and Habid F Rashvand. "Integrating Body Language Movements in Augmented Reality Learning Environment." Human-Centric Computing and Information Sciences, vol. 1, 2011.

http://www.zooburst.com

$\mathrm{Hu}$, Li-tze, and Peter M Bentler. "Cutoff Criteria for Fit Indexes in Covariance Structure Analysis: Conventional Criteria Versus New Alternatives." Structural Equation Modeling: A Multidisciplinary Journal, vol. 6, 1999.

İbili, Emin, and Sami Şahin. "Software Design and Development of an Interactive 3D Geometry Book Using Augmented Reality:ARGE3D." Afyon Kocatepe University Journal of Science and Engineering, vol. 13, 2013, pp. 1-8.

İzgi Onbaş1l1, Ü. "The Effect of Augmented Reality Practices on the Attitudes of Primary School Students towards Augmented Reality Practices and Science Motivation." Ege Journal of Education, vol. 19, no. 1, 2018, pp. 320-337. 
İçten, Tarik, and Güngör Bal. "Review of Recent Developments and Applications in Augmented Reality." Gazi University Journal of Science Part C: Design and Technology, vol. 5, no. 2, 2017, pp. 111-136.

Kara, A. Investigation of Research on the Use of Augmented Reality Practices in Education, 2018.

Karal, H., and M. S. Abdüsselam. Augmented Chemistry: Interactive Education System. 2015.

Kaufmann, H. Collaborative Augmented Reality in Education, 2003.

Kerawalla, Lucinda, et al. "Making it Real: Exploring the Potential of Augmented Reality for Teaching Primary School Science.” Virtual Reality, vol. 10, 2006, pp. 163-174.

Korkmaz, Ö. "Instructional Technology Foundations: Theories, Research." Foundations of Instructional Technology: Theories Research, Trends, 2013, pp. 431-446.

Kreijns, Karel., et al. "What Stimulates Teachers to Integrate ICT in their Pedagogical Practices? The Use of Digital Learning Materials in Education." Computers in Human Behavior, vol. 29, no. 1, 2013, pp. 217-225.

Küçük, Sevda., et al. "Augmented Reality Applications Attitude Scale in Secondary Schools: Validity and Reliability Study." Education And Science, vol. 39, no. 176, 2014, pp. 383-392.

Matcha, Wannisa, and Dayang Rohaya Awang Rambli. "Exploratory Study on Collaborative Interaction Through the Use of Augmented Reality in Science Learning." Procedia Computer Science, 2013, pp. 144-153.

Miles, M, B., and A. M. Huberman. Qualitative Data Analysis: An Expanded Sourcebook. Sage, 1994.

Rosenbaum, Eric., et al. "On Location Learning: Authentic Applied Science with Networked Augmented Realities." Journal of Science Education and Technology, vol. 16, 2007, pp. 31-45.

Salonen, Tapio, and Juha Sääski. Dynamic and Visual Assembly Instruction for Configurable Products using Augmented Reality Techniques.
Advanced Design and Manufacture to Gain a Competitive Edge, 2008, pp. 23-32.

Schreiber, James B., et al. "Reporting Structural Equation Modeling and Confirmatory Factor Analysis Results: A Review." Journal of Educational Research, vol. 99, no. 6, 2006, pp. 323-338.

Seferoğlu, Sadi S. Use of Technology in Primary Schools and Managers' Perspectives. Harran University, 2009.

Shen, Cai-Xia, et al. "Why are Children Attracted to the Internet? The Role of Need Satisfaction Perceived Online and Perceived in Daily Real Life." Computers in Human Behavior, vol. 29, no. 1, 2013, pp. 185-192.

Sin, Kien Aw, and Halimah Badioze-Zaman. "Live Solar System (LSS): Evaluation of an Augmented Reality Book-Based Educational Tool." International Symposium on Information Technology, 2010.

Sumadio, Dwistratani Desi, and Dayang Rohaya Awang Rambli. "Preliminary Evaluation on User Acceptance of the Augmented Reality Use for Education." Second International Conference on Computer Engineering and Applications, 2010.

Sirakaya, M. Effects of Augmented Reality Applications on Students' Achievement, Misconceptions and Course Engagement, 2015.

Taşkıran, A., et al. "Using Augmented Reality Application in Foreign Language Teaching." Akademik Bilişim, 2015, pp. 462-467.

Tian, K., et al. "Multi-Viewpoint Smartphone ArBased Learning System for Astronomical Observation." International Journal of Computer Theory and Engineering, vol. 6, no. 5, 2014, pp. 396-400.

Tomi, A. Bin, and Dayang Rohaya Awang Rambli. "An Interactive Mobile Augmented Reality Magical Playbook: Learning Number with the Thirsty Crow." Procedia Computer Science, vol. 25, 2013, pp. 123-130.

Toraman, Lale, and Ertuğrul Usta. "The Analysis of the Cases of Being a Digital Native and Cyber Bully of the Secondary School Students in Terms of Various Variables." Ondokuz Mayis 
University Journal of Education Faculty, vol. Y1lmaz, R. M. Effects of Three-Dimensional 37, no. 2, 2018, pp. 57-77.

TosikGün, E., and Bilal Atasoy. "The Effects of Augmented Reality on Elementary School Students' Spatial Ability and Academic Achievement." Education and Science, vol. 42, 2017, pp. 31-51.

van Krevelen, D.W.F., and R. Poelman. "A Survey of Augmented Reality Technologies, Applications and Limitations." International Journal of Virtual Reality, vol. 9, no. 2, 2010, pp. 1-20.

Wojciechowski, R., and Cellary, W. "Evaluation of Learners' Attitude toward Learning in ARIES Augmented Reality Environments." Computers \& Education, vol. 68, 2013, pp. 570-585.

Wu, Hsin-Kai, et al. "Current Status, Opportunities and Challenges of Augmented Reality in Education." Computers \& Education, vol. 62, 2013, pp. 41-49.

Yen, Jung-Chuan, et al. "Augmented Reality in the Higher Education: Students' Science Concept Learning and Academic Achievement in Astronomy." Procedia - Social and Behavioral Sciences, 2013, pp. 165-173.

Yusoff, Z., and Halina Mohamed Dahlan. "Mobile Based Learning: An Integrated Framework to Support Learning Engagement through Augmented Reality Environment." International Conference on Research and Innovation in Information Systems (ICRIIS), 2013, pp. 251-256. Storytelling Developed with Augmented Reality Technology on Narrative Skill and Creativity, 2014.

Zarzuela, M. M., et al. "Mobile Serious Game Using Augmented Reality for Supporting Children's Learning About Animals." Procedia Computer Science, vol. 25, pp. 375-381.

Özabac1, N., and Akif Olgun. "A Study on Computer Based Science and Technology Education on Students' Attitudes, Master Learning Skills and Achievement." Electronic Journal of Social Sciences, vol. 10, 2011, pp. 93-107.

Özarslan, Y. The Effect of Augmented Reality Enhanced Learning Materials on Learners' Achievement and Learners' Satisfaction, 2013.

Özbek, F. Effect of the Augmented Reality in the Elementary School 4th Grade Turkish Course on the Achievement and Motivation of the Students, 2018.

Şahin, Dilara. The Effect of Science Teaching with the Augmented Reality Technology on Secondary School Students' Achievement and their Attitude Towards the Course, Atatürk University, 2017.

Şentürk, M. The Investigation with Solomon FourGroup Design on the Effect of using Mobile Augmented Reality (AR) Applications in the Unit Titled Solar System and Beyond in the 7th Grade on the Students' Academic Success, Motivation, Science and Technology Attitude, 2018.

\section{Author Details}

Fatih Arıkan, İstanbul Rumeli University, Istanbul, Turkey, Email ID: arikanfati@gmail.com

Hasan Özgür, Associate Professor, Department of CEIT, Faculty of Education, Trakya University, Edirne, Turkey Email ID: hasanozgur@gmail.com

(*This study was produced from Fatih Arikan's Master's thesis entitled "The Design and Implementation of an Educational Augmented Reality Application for Logical Circuit Design") 